\title{
O livro proibido de Guerreiro Ramos
}

\author{
Guerreiro Ramos' forbidden book
}

El libro prohibido de Guerreiro Ramos

RICARDO RAMOS SHIOTA ${ }^{1}$

1 Universidade Estadual do Norte Fluminense Darcy Ribeiro (UENF) /
Programa de Pós-Graduação em SOCIOlogia Política, Campos dos GoYtacazes - RJ, Brasil

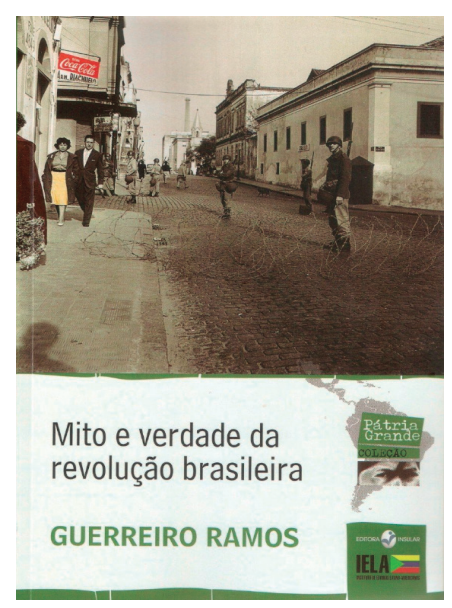

RAMOS, G. Mito e verdade da revolução brasileira. 2. ed. Florianópolis: Insular, 2016. 294 p. (Coleção Pátria Grande. Biblioteca do Pensamento Crítico Latino-Americano, 6). ISBN 9788574748481.

Palavras-chave: Guerreiro Ramos. Pensamento social. Teoria do socialismo. Teoria das organizações. Keywords: Guerreiro Ramos. Social Thinking. Theory of Socialism. Organizational Theory.

Palabras clave: Guerreiro Ramos. Pensamiento social. Teoría del socialismo. Teoría de las organizaciones.

Mito e verdade da revolução brasileira foi publicado, originalmente, no ano de 1963. Incluído no index pela Ditadura, tornou-se um livro pouco conhecido pelos leitores. Em 2016, ganhou nova edição pela Editora Insular. Trata-se de um livro que se insere numa vasta literatura sobre a revolução brasileira. Nele, Guerreiro Ramos expõe sua tese acerca da necessidade de um caminho brasileiro para o socialismo, contrapondo-se à importação de modelos de revolução. Ao conceituar o fenômeno social, distingue revolução de fenômenos sociais análogos, como golpes, guerras civis e quarteladas. Mediante o diálogo entre o pensamento social brasileiro e a categoria revolução, ligada ao socialismo e ao comunismo, Guerreiro Ramos faz a 'redução sociológica' da categoria e oferece ao leitor um livro no qual critica as raízes do stalinismo, apontando os desafios da transformação do Brasil contemporâneo.

Alberto Guerreiro Ramos (1915-1982), intelectual e político brasileiro cassado e desterrado nos EUA após o golpe de 1964, onde foi professor da Universidade do Sul da Califórnia (University of Southern California ${ }^{1}$ ), tem tido seus livros reeditados ${ }^{2} \mathrm{e}$ até disponibilizados na internet pelo site do Conselho Federal de Administração ${ }^{3}$. Recentemente, no ano de 2016, a Editora Insular publicou uma nova edição de Mito e verdade da revolução brasileira (2. ed.) como o sexto volume da Coleção Pátria Grande, que compõe a Biblioteca do Pensamento Crítico Latino-Americano, do Instituto de Estudos Latino-Americanos (IELA/ UFSC). A editora promete lançar uma coleção com um total de 80 livros clássicos da inteligência latino-americana, obras de intelectuais que romperam com o cânone eurocêntrico e possuem contribuições fundamentais para orientar uma política de superação do subdesenvolvimento e da dependência.

À luz de tais critérios, o livro escrito em contexto histórico e intelectual datado, está na contramão do processo em curso de reversão neocolonial, em que o "[...] Brasil tende a ser relegado a posição terciária de mero fornecedor de produtos primários e semimanufaturados, de baixo conteúdo tecnológico, alto consumo de energia e elevado impacto negativo sobre

\footnotetext{
${ }^{1}$ E não professor da Universidade da Carolina do Sul, como consta na orelha do livro.

Ver: Azevedo (2016, p. 24).

${ }^{3}$ Disponível em: <http://www.cra-rj.adm.br/publicacoes/acervo_digital/guerreiro-ramos/>. Acesso em: 15 jul. 2019
}

Resenha Bibliográfica recebida em 15 de janeiro de 2019 e aceita para publicação em 13 de outubro de 2019

O autor agradece à agência financiadora deste trabalho como Bolsista de Pós-Doutorado Capes/PNPD

DOI: http://dx.doi.org/10.1590/1679-395120190004 
o meio ambiente" (SAMPAIO JUNIOR, 2017, p. 133). Deste ponto de vista, a obra, publicada pela primeira vez em 1963, conserva sua exemplaridade, além de ser importante contribuição de um intelectual brasileiro para a teoria e a história das ideias do socialismo, preocupado com a soberania nacional de uma perspectiva de esquerda no momento em que EUA e URSS disputavam hegemonia na geopolítica internacional. Naqueles anos, o PTB (Partido Trabalhista Brasileiro) estava no governo, mas o Partido Comunista Brasileiro (PCB), mesmo na clandestinidade, tinha hegemonia na esquerda brasileira (BRANDÃO, 1999). Antes de Guerreiro Ramos, Celso Furtado (1962) já havia se posicionado contra o marxismo-leninismo, que conquistava simpatia da juventude universitária e do movimento estudantil, para apresentar sua interpretação do processo histórico em curso. Porém, sem fazer uma crítica abrangente e sistemática do stalinismo como o sociólogo baiano.

A nova edição de Mito e verdade da revolução brasileira tem, na orelha, texto de Nildo Ouriques e a apresentação escrita por Ariston Azevedo, conservando as demais partes da edição original. São elas: o prefácio de 1963; o capítulo I, "Pequeno Tratado Brasileiro da Revolução"; o capítulo II, "Revolução Direta e Socialismo"; o capítulo III, "Uma Corruptela da Filosofia: o Marxismo-Leninismo"; o capítulo IV, "O Morto e o Vivo no Internacionalismo Proletário"; o capítulo V, "Defesa do Revisionismo"; o capítulo VI, "Homem-Organização e Homem-Parentético"; o capítulo VII, "Revolução Brasileira ou Jornada de Otários?"; o apêndice I, "A filosofia do Guerreiro sem senso de humor"; o apêndice II, "Trabalhismo e Marxismo-Leninismo".

Inicialmente o livro se chamaria Os Rinocerontes e a Revolução Brasileira, porém, Guerreiro Ramos cedeu à sugestão do editor, contra sua preferência, e o intitulou Mito e Verdade da Revolução Brasileira, conforme o prefácio. Ele utiliza a peça Rinoceronte, de lonesco, que é contrária ao conformismo e crítica à ascensão do fascismo na Romênia, para questionar o PCB e a esquerda orientada pelo "marxismo-leninismo". Esta expressão é usada pelo autor para se referir ao stalinismo, ideologia que surge na União Soviética após a morte de Lênin, importada de modo acrítico por alguns setores da esquerda brasileira. Citações de trechos da peça de lonesco, usados como epígrafes do prefácio, dos capítulos e do anexo I do livro, elucidam a verve do autor contra aqueles com os quais se indispunha e não eram poucos.

Desentendeu-se com ninguém menos que Gilberto Freyre, Florestan Fernandes, Costa Pinto - do ponto de vista da sociologia, os maiores intérpretes do Brasil de sua geração. Pela estatura dos contendores, percebe-se a ousadia do pensamento de Guerreiro Ramos, uma capacidade mobilizada para questionar o stalinismo e a importação dessa ideologia no Brasil. Sua crítica vem acompanhada de senso de humor e de realidade, os rinocerontes eram cômicos, mas indicavam a possibilidade de uma absurda tragédia iminente. Mas, apesar de questionar o modelo de revolução do PCB e os adeptos do stalinismo, não foi anticomunista, uma vez que em seus escritos manifestou-se em defesa da legalização do partido comunista, cujo registro fora cassado em 1947.

O conteúdo do livro foi considerado subversivo após o golpe de 1964, e, como tantos outros, proibido de ser comercializado ou apreendido pela polícia, conforme denúncia do próprio autor ao discursar no parlamento como Deputado Federal eleito na Guanabara pelo PTB no dia 08 de abril de $1964^{4}$. A política de repressão e censura afetou o mercado de livros de ciências sociais.

Milhares de livros foram sumariamente confiscados de livrarias e das editoras pelas mais diversas razões: por falarem de comunismo (mesmo que fosse contra), porque o autor era persona non grata do regime, por serem traduções do russo, ou simplesmente porque tinham capas vermelhas (HALLEWELL, 1985, p. 483).

As editoras progressistas sofreram o boicote da Ditadura, que pressionava os bancos a não concederem empréstimos, e as bancas de rua e livrarias a não venderem os livros daquelas editoras. Para se ter ideia, "[...] em fins de 1978 havia perto de quinhentos livros proibidos no Brasil” (HALLEWELL, 1985, p. 501).

Ainda está para ser feita uma análise integral, ponto a ponto, de Mito e verdade da revolução brasileira, uma vez que os pesquisadores têm discutido mais as singularidades temáticas do que o conjunto de questões suscitadas pelo livro. Entre eles, destaca-se o artigo de Luiz Eduardo Motta (2010), que, a despeito de não abordar toda a problemática do livro, é pioneiro ao elucidá-lo sob o prisma das questões que envolvem o nacionalismo, o terceiro-mundismo e a rejeição de Guerreiro Ramos ao modelo de revolução do PCB. Motta revela que, nesta crítica ao PCB, Guerreiro Ramos adere ao nacionalismo revolucionário, anti-imperialista, terceiro-mundista e, por conseguinte, rompe com o credo desenvolvimentista.

\footnotetext{
${ }^{4}$ Quem melhor chamou atenção para essa denúncia foi Pizza Junior (1997). O documento que contém a fala de Guerreiro Ramos está arquivado em: <http:// imagem.camara.gov.br/Imagem/d/pdf/DCD09ABR1964.pdf\#page=19>. Acesso em: 01 nov. 2018.
} 
Motta (2010) discorda de Caio Navarro Toledo (2007, p. 311), para quem “[...] o nacionalismo de Guerreiro Ramos buscava, assim, conciliar uma sociologia 'ideologicamente' de esquerda com uma política desenvolvimentista tipicamente liberalburguesa". De fato, passa despercebido que Ramos, após deixar o Instituto Superior de Estudos Brasileiros (ISEB) em 1958, rompe com o desenvolvimentismo e com a visão da liderança da burguesia nacional no processo da revolução brasileira. Além disso, Toledo equivoca-se ao dizer que, na visão do sociólogo isebiano, "[...] o proletariado brasileiro estaria opondo-se aos interesses do conjunto da nação, caso viesse lutar pela destruição da ordem burguesa no país ou viesse lutar diretamente pela implantação do socialismo" (TOLEDO, 2007, p. 311). Contudo, nas palavras do próprio sociólogo baiano,

[...] a nação é um conceito essencialmente burguês, valor essencial da revolução burguesa [...]. A classe operária hoje, nos países subdesenvolvidos, conhecendo a história decorrida das revoluções burguesas no Velho Mundo, adere com ironia ao nacionalismo e aos nacionalistas. Mas ela não é nacionalista. Por essência, ela é internacionalista. Sua vocação não é a nação. É a comunidade humana universal. Para a classe operária, o nacionalismo é uma ideologia de circunstância (RAMOS, 2016, p. 282-283).

A leitura de A crise do poder no Brasil, de Guerreiro Ramos (1961), é reveladora e contraria a afirmação segundo a qual manteve-se partidário do desenvolvimentismo. Em vez disso, conforme Motta (2010), os posicionamentos do autor em defesa do nacionalismo anti-imperialista e do socialismo, na conjuntura que antecedeu ao golpe de 1964, presentes em Mito e verdade da revolução brasileira, decorrem da análise das revoluções e do socialismo no Terceiro Mundo e tiveram continuidade na teoria marxista da dependência, em autores como Ruy Mauro Marini e Theotonio dos Santos.

No Prefácio de Mito e verdade da revolução brasileira, são expostos os critérios, os motivos e os planos originais que suscitaram a escrita e publicação do livro. $O$ autor expõe dois critérios para fazer a crítica ao stalinismo: um de natureza cultural, o uso acrítico de teorias estrangeiras; outro de ordem organizacional, a reprodução do modelo organizacional e das diretrizes vigentes no Partido Comunista da União Soviética (PCUS) pelo PCB. Ambos os critérios, que estão no cerne da obra pregressa de Guerreiro Ramos, resultam de uma apropriação das críticas de Alberto Torres a "todas as ideias a priori da política" (TORRES, 1978, p. 61) e às formas estranhas à realidade brasileira, e de Oliveira Vianna $(1955,1987)$ ao idealismo utópico. A intenção de erigir uma sociologia nacional voltada para a superação do subdesenvolvimento e da condição colonial ilumina as críticas intransigentes do autor à sociologia brasileira (RAMOS, 1995) e adquire fundamentação teórica no livro A redução sociológica ${ }^{5}$.

Em 1966, Caio Prado Júnior publicou A revolução brasileira, no qual são usados os mesmos critérios, porém de outra perspectiva (marxista) e em outro objeto: o programa político do PCB, que, embasado na interpretação equivocada da realidade brasileira, teria colaborado para a queda do governo de João Goulart. Questiona "[...] conceitos formulados a priori e sem consideração adequada dos fatos; procurando-se, posteriormente, e somente assim - o que é mais grave - encaixar nesses conceitos a realidade concreta" (PRADO JÚNIOR, 1978, p. 29). O programa nacional-democrático, por estar completamente alheio à história brasileira, teria comprometido toda a organização e ação do partido; concepções teóricas e esquemas de ação do PCB são o alvo da crítica de Caio Prado Júnior, filiado ao partido. Ambos os livros, de Caio Prado Júnior e Guerreiro Ramos, complementam-se. Não foi feito ainda um estudo comparativo, abrangendo as décadas de 1940 a 1960, já que ambos têm afinidades eletivas, como o nacionalismo radical e a aspiração de formular uma teoria enraizada na história brasileira, oferecendo uma interpretação global do Brasil, embora tenham perspectivas teóricas distintas. Além disso, Caio Prado Júnior é citado e elogiado pelo autor (RAMOS, 1995).

No primeiro capítulo, "Pequeno tratado brasileiro da revolução", o autor faz uma revisão teórica, conceitual e propõe modelos para pensar este fenômeno da transformação social. Há uma contribuição para diferenciar revolução de golpe de Estado, fenômenos sociais análogos, mas distintos, como insurreição, guerra civil, movimentos armados e quarteladas (SHIOTA, 2018). Para o sociólogo baiano, esses fenômenos sociais eram revolucionários apenas nos períodos em que não existia a classe operária, quando as transformações ocorriam pela ação da minoria dos setores dominantes. Na contemporaneidade,

[...] revolução é o momento, subjetivo e objetivo, em que uma classe ou coalizão de classes, em nome dos interesses gerais, segundo as possibilidades concretas de cada momento, modifica ou suprime a situação presente, determinando mudanças de atitude no exercício do poder pelos atuais titulares e/ ou impondo o advento de novos mandatários (RAMOS, 2016, p. 62).

${ }_{5}^{5}$ Uma análise contextual seguida de um balanço da importância desse livro pode ser encontrada em Bariani Junior (2015). 
A definição, pautada na revisão de escritos de revolucionários (Blanqui, Marx, Lenin e Lukács), destaca o exercício do poder e a particularidade de cada forma política, congruente com a tese defendida no livro de que é preciso encontrar um caminho brasileiro para o socialismo. "A revolução é movimento consciente que visa a efetivar uma possibilidade objetiva e está só pode ser conhecida concreta e objetivamente enquanto situada numa totalidade. Por isso não há modelos uniformes de revolução. Cada uma é questão específica" (RAMOS, 2016, p. 72).

O critério mudança de conteúdo no poder de uma sociedade serve para Guerreiro Ramos sistematizar uma tipologia de quatro possibilidades, conforme os meios empregados, da mudança política: 1) circulação de elites ou modificação de sua composição sem perda do poder; 2) derrocada, quando há o assalto ao poder assegurado pelas armas, usado pelo marxismo-leninismo; 3) revolução assumida - quando um círculo dominante atende às reivindicações das camadas sociais radicalizadas, mas conforme o interesse do desenvolvimento de possibilidades contidas no sistema econômico e social vigente; 4) revolução direta, um constructo puramente teórico que ocorrerá quando a maioria assumir as funções de reconstrução social e não delegá-las a um grupo restrito que a representa. Esse modelo almejado pelo autor pressupõe aquilo que chama de atitude parentética.

Guerreiro Ramos usa o conceito de revolução de forma processual, recusa as concepções insurrecionais e épicas e defende o aperfeiçoamento democrático, isto é, a necessidade de transformar as regras do jogo político visando à ampliação da democracia representativa. Para ele, os partidos brasileiros não expressavam diferenças ideológicas. Já não controlavam a situação política do país. A revolução era uma potencialidade contida na crise das instituições políticas e organizativas, as quais estavam desajustadas da nova realidade social engendrada pela Revolução de 1930 e pela emergência do povo na vida política em 1946, quando uma camada numerosa e livre da população brasileira se torna capaz de contrariar os desígnios de governantes e chefes locais para impor sua vontade nas urnas, ao contrário do que ocorria na Primeira República. Mas faltavam os sujeitos com virtù para tornar a revolução brasileira uma realidade. Não se tratava de uma realidade histórica semelhante à soviética, chinesa, cubana, nas quais a revolução ocorreu mediante a guerra civil ou tomada do poder pela força, dando origem a regimes políticos cuja concepção de organização seria capitalista e não socialista.

A defesa do primado da decisão política face ao determinismo econômico nas situações revolucionárias e a defesa de uma teoria da revolução extraída das particularidades históricas vão ao encontro dos últimos escritos de Karl Marx, revelados na correspondência trocada com ativistas russos entre 1877-1894, conhecidos por intermédio de documentos de Maximilien Rubel, citados por Guerreiro Ramos e publicados, há poucos anos, em Marx e Engels (2013).

Nestes últimos escritos de Marx há, nas entrelinhas, uma "[...] perspectiva dialética, policêntrica, que admite uma multiplicidade de formas de transformação histórica, e, sobretudo, a possibilidade que as revoluções sociais modernas comecem na periferia do sistema capitalista e, não como afirmavam seus escritos anteriores, no centro" (LOWY, 2013, p. 9). Perspectiva que rompe com a interpretação unilinear, eurocêntrica e etapista do materialismo histórico, muito vigente no contexto intelectual das décadas de 1950 e 1960. Marx (2013) afasta-se do economicismo ao cogitar a possibilidade da transição socialista assentada nas comunas rurais russas, sem o desenvolvimento prévio capitalista. Reprova os usos de sua teoria por aqueles que formalizam ou generalizam seu "[...] esquema histórico da gênese do capitalismo na Europa ocidental em uma teoria histórico-filosófica do curso geral fatalmente imposto a todos os povos, independentemente das circunstancias históricas nas quais se encontrem [...]" (MARX, 2013, p. 68). "Não fazem revolução os que acreditam numa teoria final da revolução" (RAMOS, 2016, p. 82), como resumia Guerreiro Ramos.

No segundo capítulo, "Revolução direta e socialismo", desenvolve o que entende por revolução direta, valendo-se de intelectuais como Max Adler, Kautsky, Ernest Mendel, Maximilien Rubel, Daniel Guérin e Rosa Luxemburgo, para criticar a URSS e defender que ali não havia socialismo, mas capitalismo de Estado. O modelo de revolução direta baseia-se no papel ativo da maioria do povo na participação da reconstrução social. "Até a presente data, ainda não se concretizou revolução desse tipo" (RAMOS, 2016, p. 102), ressalva o autor. Nesse ponto, por mais justas que possam ser consideradas as críticas, termina por contradizer um princípio adotado na formulação de seu conceito de revolução, apropriando-se de Marx: "[...] a revolução não é um estado que deve ser criado, ideal a orientar a realidade; é movimento efetivo que, segundo as possibilidades concretas de cada momento, suprime a situação presente" (RAMOS, 2016, p. 58).

Guerreiro Ramos também recua frente às afirmações do capítulo anterior por pautar a crítica à URSS pelo baixo nível econômico no momento da revolução, subordinando a construção do socialismo nos países periféricos ao desenvolvimento das forças produtivas. Desse ângulo, define o socialismo como método político e econômico de desenvolvimento das forças produtivas no qual "[...] o Estado assume o papel de único empresário [que] organiza a produção segundo o critério do interesse público" 
(RAMOS, 2016, p. 115); meio para promover o desenvolvimento capitalista acelerado nas nações periféricas. Somente "[...] poderá vingar no Brasil, na medida em que for gerado pelas condições particulares da história do nosso povo" (RAMOS, 2016, p. 294). O socialismo defendido pelo autor seria transformação em defesa da soberania nacional, alcançada de forma pacífica no processo político institucional democrático com horizonte humanista. Vale lembrar que o livro foi escrito em 1963, dez anos antes da queda do governo de Salvador Allende no Chile, também partidário do socialismo democrático e pluripartidário.

No terceiro capítulo, "Uma corruptela da filosofia: o marxismo-leninismo", Guerreiro Ramos desconstrói a ideia do desvio psicológico de Stalin. Critica o stalinismo, evidencia as raízes sociais e culturais do fenômeno político do stalinismo, suas origens na intelligentzia russa e na recepção que esta fez dos escritos de Marx e Engels, mediada pelo "messianismo, dogmatismo e voluntarismo" da tradição local. Retorna a Marx, Engels e Lenin para afastá-los da doutrina, da interpretação de seguidores e vulgarizadores organizados em partidos políticos comunistas que seguiam as regras do PCUS. Na história dos "movimentos libertários" identifica a "lei de Bronze", "[...] segundo a qual, a partir de certo momento, os representantes autênticos tendem a ser substituídos e até derrocados por ativistas e falsários" (RAMOS, 2016, p. 130). Surge, assim, o marxismo-leninismo, que, neste livro resenhado, refere-se ao stalinismo, ao PCUS, ao regime soviético após a morte de Lenin e à tomada do poder por Stálin. O stalinismo foi criado como ideologia oficial para impedir a crítica e promover a expansão do regime. Diversos intelectuais foram afetados e Guerreiro Ramos usa as ideias, a história de vida de Lukács, Brecht e diversos outros intelectuais marxistas citados para sustentar os argumentos contrários ao stalinismo.

No quarto capítulo, "O morto e o vivo no Internacionalismo Proletário", é feita uma análise das diferenças, dos aspectos positivos e negativos do internacionalismo operário organizado desde os primórdios no século XIX - com destaque à Primeira Internacional, à Segunda Internacional e à Terceira Internacional -, objetivando retificar concepções teóricas e práticas obsoletas e lesivas ao esforço de emancipação dos trabalhadores. A despeito de reconhecer a importância do internacionalismo soviético (Comintern e Cominform) para consolidar a Revolução de 1917, o autor defende que a história teria tornado essas poderosas organizações obsoletas e contrarrevolucionárias, na medida em que se converteram em razão de Estado e "[...] ideologia de domesticação do proletariado" (RAMOS, 2016, p. 176). Sustenta a impossibilidade de identificar o socialismo com o regime político de algum país dito socialista. $O$ internacionalismo proletário serve para institucionalizar a solidariedade ativa das massas em defesa do socialismo. A internacionalidade da causa dos trabalhadores, contudo, é mediada por diferentes vias nacionais de transição, de modo que "[...] lutando por reivindicações nacionais próprias, cada movimento operário luta pelo advento mundial do socialismo" (RAMOS, 2016, p. 181). Essas ideias coadunam-se com a formulação de diversos intelectuais em defesa do socialismo terceiro-mundista (MOTTA, 2010).

No quinto capítulo, "Defesa do revisionismo", é delineada uma história da recepção do pensamento de Karl Marx nas organizações político-partidárias e explicitadas as razões pelas quais, entre 1924 e 1953, o revisionismo se converteu em tabu e motivo de coerção e até eliminação física de seus protagonistas. Para ele, revisionismo é concebido "[...] como exercício da crítica, independente de todo critério de conveniência, que não seja o da objetividade da verdade" (RAMOS, 2016, p. 202). 0 monopólio da interpretação de Marx pelo PCUS, sob domínio de Stalin, representou uma luta pela consolidação, expansão do poder e da hegemonia ideológica soviética, motivo pelo qual desaparece a tolerância para com os revisionistas. Sobretudo no interregno stalinista, o PCUS exerceu o "[...] papel de Santo Ofício na interpretação do marxismo" (RAMOS, 2016, p. 190). Ao elaborar o estado da arte do revisionismo naquele momento, o autor distingue cinco correntes, apontando as circunstâncias históricas subjacentes a tal movimento. Além de defender o revisionismo contra a interpretação stalinista do marxismo, vista como empecilho para a formação da teoria nacional da revolução no Brasil, indica a necessidade de superação do marxismo no sentido dialético de superação-conservação, de concebê-lo como parte da ciência social, desenvolvê-lo e não o tomar como produto acabado.

No sexto capítulo, "Homem-organização e Homem parentético", é tematizado o problema da organização do ponto de vista da teoria política do socialismo e proposta a atitude parentética com base no existencialismo, na sociologia do conhecimento e na sociologia política. São discutidos autores como Ferdinand Tönnies, Karl Mannheim, Wright Mills, Norbert Wiener e Robert Michels. Segundo Guerreiro Ramos, a organização é chave da servidão e da emancipação, confere poder aos agentes sobre si e sobre as circunstâncias ante a tendência espontânea da vida social à desagregação. O tema da organização já houvera havia sido objeto de reflexão de Guerreiro Ramos em sua tese, "A sociologia industrial - Formações, tendências atuais", de 1949, para ingresso no Departamento Administrativo do Serviço Público (DASP). Em 2009, foi republicada pelo Conselho Federal de Administração com o título "Uma introdução ao histórico da organização racional do trabalho". Neste texto, o autor pondera as limitações históricas do fordismo e do taylorismo em regiões nas quais a indústria era incipiente, como na América Latina. 
Em Mito e verdade da revolução brasileira, o tema da organização é apresentado em sua conexão com o político e com a política, mostrando que, como um ente social, ela pode servir para a dominação ou contribuir para a emancipação.

Contra os males da organização, "segredo da servidão humana", propõe um antídoto: a atitude parentética, exame da ação humana do prisma organizacional, "vontade refletida", reflexão sobre os condicionantes da existência social, crítica, comportamento crítico e horizonte de emancipação. Com base na fundamentação desse conceito do ângulo da organização, critica a teoria do partido único, da ditadura do proletariado e do centralismo democrático, defendidos por Lenin, Lukács e pelo stalinismo, como "produto da ideologia burguesa" (RAMOS, 2016, p. 236). Era ciente de que sem práxis a crítica por si mesma não transforma as relações. "Só a organização corrige os malefícios de uma organização ilegítima ou caduca [...]. Assim, a luta contra uma organização mistificada não pode ser a mera crítica e denúncia de seus aspectos negativos, mas a sua substituição por outra organização, adequada aos novos critérios válidos" (RAMOS, 2016, p. 218). Ensinamentos muito atuais desse arquiteto institucional.

No sétimo e último capítulo, "Revolução brasileira ou jornada de otários?", a discussão sobre revolução é subsumida ao caso brasileiro na conjuntura que antecedeu o golpe de 1964, vista como situação revolucionária peculiar, sem dualidade de poderes e na qual as forças de esquerda estavam representadas no governo. A história do país e a referência aos intelectuais brasileiros são marcantes nesse capítulo, em que é feito um diagnóstico de como a crise do poder se manifestava e quais eram as possibilidades objetivas para a revolução brasileira, entre as quais citava a do fracasso. A transformação é definida como "[...] reorganização institucional, tendo em vista reajustar o Estado, não só tornando-o reflexo da correlação de classes dominantes hoje na sociedade, por força de seu desenvolvimento nas últimas décadas, como também para habilitá-lo para novas funções" (RAMOS, 2016, p. 251). Proposição resultante da análise de um padrão particular do fenômeno revolucionário no Brasil, presente na Revolução de 1930 e no Golpe de Estado de 1937, caracterizado por "[...] modificações institucionais de envergadura e o advento de novo conteúdo de classe no balanço do poder" (RAMOS, 2016, p. 255). Por este motivo, o critério do autor é a recomposição, "com o novo conteúdo de classe, o diretório político da nação" (RAMOS, 2016, p. 251). Essa conceituação afasta o golpismo, a derrocada, a guerra civil e propõe mudanças institucionais.

No anexo I, "A filosofia do Guerreiro sem senso de humor", há uma resenha bastante crítica do livro de Álvaro Vieira Pinto, Consciência e realidade nacional. No Apêndice II, é reproduzida uma declaração do PTB redigida pelo autor, "Trabalhismo e Marxismo-Leninismo". A tese defendida pelo autor em Mito e verdade da revolução brasileira aparece nesse documento: "[...] o PTB, na defesa dos interesses das massas obreiras, proclama a sua vocação socialista, mas não admite nenhum figurino pré-fabricado de socialismo, o qual só poderá vingar no Brasil, na medida em que for gerado pelas condições particulares da história do nosso povo" (RAMOS, 2016, p. 294).

Das possibilidades objetivas identificadas pelo sociólogo, não vingou revolução nem jornada de otários, mas a contrarrevolução. A história revelou que os rinocerontes estavam no campo político oposto ao de Guerreiro Ramos, para usar suas palavras, extraídas de sua tipologia, eram os "círculos conservadores", que repeliram "com eficácia, ameaça grave aos seus interesses essenciais" (RAMOS, 2016, p. 261). Os rinocerontes não eram os comunistas e demais companheiros de viagem com os quais Guerreiro Ramos se desentendeu. A "rinocerontite", na verdade, estava se processando no outro polo político, nas forças sociais adversárias da revolução brasileira e das reformas de base, justamente aquelas que colocaram seu livro no index.

Com efeito, o golpe de 1964, ao interromper a curta trajetória política parlamentar de Guerreiro Ramos, também inviabilizou a continuidade das reflexões sobre teoria e história das ideias da revolução, do nacionalismo e do socialismo presentes nesse livro, uma vez que a sociedade brasileira seguiu o caminho contrário ao que desejava. Exilou-se, então, nos EUA, onde fez carreira como professor universitário.

Mito e verdade da revolução brasileira insere este sociólogo baiano na linhagem de intelectuais brasileiros e latino-americanos que viram no "[...] socialismo, um modo de resolver a questão nacional e a questão social, em conjunto" (IANNI, 1988, p. 19). Porém, na formulação dele não convinha ao país importar um modelo de revolução socialista adverso à própria realidade. Desse modo, ao questionar a validade da exportação de modelos de revolução socialista, o sociólogo tece uma reflexão sobre até que ponto as experiências socialistas históricas seriam soluções de caráter universal. Guerreiro Ramos enfrentou com muita erudição e argúcia um problema colocado no âmbito da teoria política, fazendo uso de intelectuais marxistas e não marxistas para defender sua tese acerca da necessidade de um caminho brasileiro para o socialismo ${ }^{6}$.

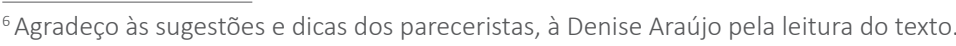




\section{REFERÊNCIAS}

AZEVEDO, A. Apresentação. In: RAMOS, G. Mito e verdade sobre a revolução brasileira. 2. ed. Florianópolis: Insular, 2016.

BARIANI, E. Certidão de nascimento: a redução sociológica em seu contexto de publicação. Caderno CRH, Salvador, v. 28, n. 73, p. 15-25, jan./abr. 2015.

BRANDÃO, G. M. A esquerda positiva: as duas almas do Partido Comunista (1920/1964). São Paulo: Hucitec, 1999.

FREIRE, A. O social-trabalhismo do deputado federal Guerreiro Ramos. Cadernos EBAPE.BR, Rio de Janeiro, v. 13, n. esp., set. 2015.

FURTADO, C. A pré-revolução brasileira. Rio de Janeiro: Editora Fundo de Cultura, 1962.

HALLEWELL, L. O livro no Brasil (sua história). São Paulo: T. A. Queiroz; EDUSP, 1985.

IANNI, O. A questão nacional na América Latina. Estudos Avançados, São Paulo, v. 2, n. 1, p. 5-40, jan./mar. 1988.

LOWY, M. Introdução - Dialética revolucionária contra a ideologia burguesa do Progresso. In: MARX, K.; ENGELS, F. Luta de classes na Rússia. São Paulo: Boitempo, 2013.

MARX, K.; ENGELS, F. Luta de classes na Rússia. São Paulo: Boitempo, 2013.

MOTTA, L. E. A política do Guerreiro: nacionalismo, revolução e socialismo no debate brasileiro nos anos 1960. Organizações \& Sociedade, v. 17, n. 52, p. 85-101, 2010.

PIZZA JUNIOR, W. Trajetória parlamentar de Alberto Guerreiro Ramos. Revista de Administração Pública, Rio de Janeiro, v. 31, n. 5, p. 24-28, set./out. 1997.
PRADO JÚNIOR, C. A revolução brasileira. 6. ed. São Paulo: Brasiliense, 1978.

RAMOS, G. A crise do poder no Brasil: problemas da revolução nacional brasileira. Rio de Janeiro: Zahar Editores, 1961.

RAMOS, G. Mito e verdade sobre a revolução brasileira. Rio de Janeiro: Zahar, 1963.

RAMOS, G. Introdução crítica à sociologia brasileira. 2. ed. Rio de Janeiro: Ed. UFRJ, 1995.

RAMOS, G. Mito e verdade sobre a revolução brasileira. Florianópolis: Insular, 2016.

SAMPAIO JUNIOR, P. A. Crônica de uma crise anunciada. Crítica à economia política de Lula a Dilma. São Paulo: SG Amarante, 2017.

SHIOTA, R. R. Brasil: terra da contrarrevolução. Revolução brasileira e classes dominantes no pensamento político e sociológico. Curitiba: Appris, 2018.

TOLEDO, C. N. Intelectuais do Iseb, Esquerda e Marxismo. In: MORAES, J. Q. (Org.). História do marxismo no Brasil. Teorias e interpretações. 2. ed. Campinas: Ed. Unicamp, 2007.

TORRES, A. A Organização Nacional: primeira parte. 3. ed. São Paulo: Nacional, 1978.

VIANNA, O. Instituições políticas brasileiras. v. 2. Metodologia do direito público. Rio de Janeiro: José Olympio, 1955.

VIANNA, O. Populações meridionais do Brasil. v. 1. Populações do Centro-Sul. 3. ed. Belo Horizonte: Itatiaia, Ed. UFF, 1987. 